\title{
MINERÍA AURÍFERA ILEGAL EN EL RESGUARDO INDÍGENA ALTO ANDÁGUEDA
}

\author{
Diana Lorena EcheVerry OSORIO \\ SANDRA Díaz Ricardo \\ Escuela de Posgrados de la Policía \\ Miguel Antonio Lleras Pizarro
}

\section{Resumen}

El resguardo indígena embera katío del río Alto Andágueda está siendo afectado por uno de los problemas nacionales más importantes, denominado minería ilegal, lo cual altera los componentes sociales, culturales, económicos y ambientales de los nativos del lugar y vulnera sus derechos fundamentales. Esto trae como consecuencia la presencia de delitos conexos como extorsión, explotación infantil y violación, entre otros, además de una nefasta destrucción del ambiente, por lo que amerita una revisión de responsabilidades y participación de las entidades comprendidas en las ramas del poder público colombiano para atender la problemática en este resguardo indígena.

Palabras clave: extracción de minerales, minería, ambiente, patrimonio natural.

\section{Las autoras:}

Diana Lorena Echeverry Osorio, ingeniera Ambiental. Estudiante de Especialización, Universidad Central del Valle del Cauca. Correo electrónico: diana.echeverry1197@correo.policia.gov.co Sandra Díaz Ricardo, ingeniera Ambiental. Estudiante de Especialización, Universidad Manuela Beltrán. Correo electrónico: sandra.diaz@ambientebogota.gov.co

Recibido: 15 de noviembre de 2015; evaluado: 23 de enero de 2016; aceptado: 1 de febrero de 2016. 


\title{
ILLEGAL GOLD MINING IN THE INDIGENOUS RESERVATION OF THE ALTO ANDÁGUEDA
}

\author{
Diana Lorena Echeverry Osorio \\ SANDRa Díaz Ricardo \\ Escuela de Posgrados de la Policía \\ Miguel Antonio Lleras Pizarro
}

\begin{abstract}
The Embera Katío indigenous reservation of the Alto Andágueda river is being affected by one of the most important national problems called illegal mining, which alters the social, cultural, economic, and environmental aspects of the native population and violates their fundamental rights. Consequently, there is a strong presence of related crimes such as extortion, child exploitation, and rape, among others, in addition to the disastrous destruction of the environment. This warrants a review of the responsibilities and participation of the Colombian public entities in order to address the problem in this indigenous reservation.
\end{abstract}

Keywords: mineral extraction, mining, environment, natural heritage.

\section{About the authors:}

Diana Lorena Echeverry Osorio: environmental engineer. Student in specialization, Universidad Central del Valle del Cauca. Email: diana.echeverry1197@correo.policia.gov.co Sandra Díaz Ricardo: environmental engineer. Student in specialization, Universidad Manuela Beltrán. Email: sandra.diaz@ambientebogota.gov.co

Received: November 15, 2015; reviewed: January 23, 2016; accepted: February 1, 2016. 


\section{Introducción}

La minería es una actividad que busca extraer los minerales de manera óptima y eficiente y consiste en retirar el mineral de la tierra, con lo que se arrasa material vegetal fértil, nativo de la región, pues el movimiento de grandes cantidades de materiales impacta el relieve, el paisaje, las corrientes hídricas superficiales, la fauna y flora del lugar, entre otras variables y componentes biofísicos del ecosistema del lugar explotado.

Cuando esta actividad es ilícita, contribuye al surgimiento o a la expansión de problemas comunes desestabilizadores de la seguridad y convivencia ciudadana y contribuye al quebrantamiento de la integridad de las poblaciones que habitan este territorio minero.

El resguardo indígena embera katío del río Alto Andágueda no es ajeno a este asunto y por ello es necesario identificar los roles de los entes de la ramas del poder público (Legislativo, Ejecutivo y Judicial) en la problemática ambiental que presenta el resguardo a causa de la minería aurífera ilegal. En la actualidad, cuenta con un alto grado de afectación a estos recursos naturales por dicha actividad, lo que representa una amenaza latente a la supervivencia de este territorio indígena y de este valioso patrimonio ambiental y cultural del país.

Por lo anterior, es necesario conocer si la explotación aurífera, revestida de un carácter de ilegalidad, vulnera los derechos fundamentales del pueblo embera katío en su resguardo. De acuerdo con lo evidenciado, se presume que sí, ya que la actual actividad de explotación ilegal afecta de manera directa algunos de los derechos fundamentales estipulados en el Título II de la Constitución Política de Colombia de 1991.

El resguardo indígena del Alto Andágueda y su problemática de minería ilegal tiene una influencia significativa, ya que contiene 50.000 hectáreas y se encuentra ubicada al oriente del departamento del Chocó, en límites con Antioquia y Risaralda, en el centro del Nudo de San Fernando, en donde nacen varios de los ríos principales del Chocó y por donde corren los ríos Azul y Colorado.

En primer lugar, esta situación ha arrasado con innumerables hectáreas de bosque. Hoy en día, se observan gigantescas grietas en la tierra, producto de la excavación con el fin de encontrar el precioso metal; además, de los cauces de los ríos del 
Chocó se extraen a diario toneladas de arena y agua para hallar el oro. Los daños son diversos, puesto que para separar y extraer el oro de las rocas se usa mercurio, el cual llega a las aguas cuando los mineros vierten nuevamente el material al lecho del río combinado con este elemento letal para la salud de los seres humanos y la ictiofauna circundante.

Dada la exposición de los factores negativos en los componentes mencionados se pretende analizar la problemática social y ambiental que presenta el resguardo indígena del río Alto Andágueda mediante una investigación cualitativa y descriptiva, y revisar las responsabilidades de los entes gubernamentales del poder público en lo referente a la explotación ilegal de los recursos naturales y violación a la integridad étnica, social y cultural de las comunidades indígenas en sus territorios que, día a día, están viendo amenazada la subsistencia.

Como escenario ideal para la superación de la problemática, se debe orientar esfuerzos por parte de las entidades competentes adscritas a las Ramas Ejecutiva, Legislativa y Judicial para contrarrestar el desastre ambiental que está generando este conflicto.

El caso específico en el resguardo indígena Alto Andágueda evidencia la ausencia de la intervención de entidades del Gobierno para devolver a los nativos la tierra que reclaman sin la actividad minera.

\section{Contextualización de la problemática ambiental de minería ilegal en el resguardo indígena embera katío}

La minería en Colombia formó parte de las actividades de los ancestros que habitaron ese territorio. El oro fue usado por pueblos indígenas, negros, afrocolombianos y raizales para fabricar diversos objetos que reflejaban su identidad y sus costumbres.

Aunque la minería es una actividad practicada hace miles de años, la problemática empezó a surgir desde la mitad de la década pasada, cuando esta ocupación se convirtió en un "negocio" altamente rentable por el bum de los precios internacionales de los metales. 
En Colombia, la producción minera y de hidrocarburos se realiza en unos pocos departamentos, en los cuales se ha producido un brusco cambio de actividad, al pasar de la agricultura y la industria al sector minero.

En el caso del oro, entre el año 2006 y 2008 la extracción de este mineral se concentraba en el departamento de Antioquia, pero a partir del año 2009 en el departamento del Chocó se empieza a incrementar de manera acelerada llegando a un $39 \%$, cercano al $42 \%$ de Antioquia, el otro $19 \%$ se da en la mayoría de departamentos del país. ${ }^{1}$

En el departamento del Chocó, la extracción del oro se ha convertido en la principal actividad económica. Allí, la minería ilegal supera a la legal; esta última hace referencia a contar con un título minero para extraer el metal. La falta de políticas públicas claras por parte del Estado deja enormes vacíos institucionales que son aprovechados por grupos al margen de la ley para apropiarse del negocio.

Las zonas afectadas en Colombia por el abuso en la explotación del oro son innumerables y, con ellas, los daños ambientales, sociales y otros que van de la mano de esta problemática. En este artículo se toma como caso de estudio el resguardo del río Andágueda.

El resguardo del río Andágueda (también conocido como Tahami y del Alto Andágueda) está ubicado en el municipio de Bagadó departamento del Chocó, cuya extensión territorial es de 50.000 hectáreas, el cual constituye más del $50 \%$ del municipio, limitando por el nororiente con los municipios de Andes y Betania (Antioquia), por el suroriente con el municipio de Mistrató (Risaralda), en la zona noroccidental con los municipios del Carmen y Lloró (Chocó) y por el sur con el municipio de Pueblo Rico y con el Consejo Comunitario Mayor de la Opaca, COCOMOPOCA (Bagadó-Chocó). ${ }^{2}$

Estos territorios ancestrales han sido permeados por este flagelo nacional denominado minería ilegal, lo que demuestra tanto la ausencia de políticas públicas claras que comprometan mayores esfuerzos de las instituciones para combatir esta alerta nacional, como el poco control que estas ejercen para combatir el fenómeno.

Luis Jorge Garay Salamanca, Minería en Colombia. Institucionalidad y territorio, paradojas y conflictos (Bogotá: Contraloría General de la Nación, 2013), 58.

2 Tribunal Superior del Distrito Judicial de Antioquia, Sala Civil especializada en restitución de tierras, Sentencia 007 de 23 de septiembre de 2014, M. P. Vicente Landínez Lara. 
Las comunidades titulares de este territorio se dividen en 3 zonas:

Zona 1: Mazura, Uripa, Palma, Conondo, Aguasal, Alto Chichidó, Cevedé, Dos quebradas, Bajo Currupipi y Quimpara.

Zona 2: Península, Río Colorado, Matecaña, Ocotumbo, Alto Andiadó, Cascajero, Churina, Alto Playa, Alto Murindó, Brisa, Pescadito, Paságueda, Iracal, El Salto, Quebrada Monte, Mojarrita e Iguanero.

Zona 3: Vivicora, Limón, Palmira, Santa Isabel y Mutatá.

[...] Los habitantes son indígenas pertenecientes a la familia lingüística Chocó, con la variedad dialectal embera del Alto San Juan, zona del río Andágueda. Se considera (según datos del año 2012) que son 31 comunidades, 1454 familias y 7270 individuos. $^{3}$

El resguardo indígena objeto de estudio:

[...] fue constituido y reconocido por el INCODER mediante Resolución 0185 del 13 de diciembre de 1979, ratificando la Constitución Nacional de 1991 su carácter especial de propiedad colectiva y no enajenable, imprescriptible e inalienable, de especial protección por la diversidad étnica y cultural que constituye la nación y con reconocimiento de los derechos fundamentales relacionados con su autonomía y jurisdicción especial indígena. ${ }^{4}$

Dada la ubicación del sitio objeto de estudio, se destaca que su paisaje y su remoto acceso han favorecido la presencia de los grupos al margen de la ley en todas sus denominaciones, lo que ha ocasionado constantes luchas armadas por el control territorial entre estos grupos. Asimismo, existe presencia de miembros de la Fuerza Pública en la zona.

A causa de estos enfrentamientos armados, las comunidades indígenas del resguardo se ven expuestas a múltiples delitos como desplazamiento forzado, violación, prostitución y trabajo infantil, entre otros delitos aberrantes que hacen que la armonía natural y cultural de la zona se extinga poco a poco.

Para las comunidades pertenecientes al resguardo indígena del Alto Andágueda, la minería ilegal ha traído como consecuencia una situación caótica de violencia

Tribunal Superior del Distrito Judicial de Antioquia, Sala Civil especializada en restitución de tierras, Sentencia 007.

4 Tribunal Superior del Distrito Judicial de Antioquia, Sala Civil especializada en restitución de tierras, Sentencia 007. 
armada, protagonizada por grupos armados, incluida la Fuerza Pública, que desemboca en el desplazamiento de un gran número de los habitantes nativos del lugar a centros poblados como Medellín y Bogotá.

La minería ilegal ofrece una rentabilidad muy significativa para financiar las estructuras de los grupos armados ilegales; es por ello que la han adoptado como fuente de su economía por la cantidad de recursos que recauda, sin medir las reprochables consecuencias sociales y la devastación ambiental del territorio indígena.

Entre los años 2012 y 2015 se ha evidenciado que tanto las FARC como las bandas criminales (Bacrim) se lucran de esta actividad ilegal. ${ }^{5}$

Debido al poco control que ejerce el Estado en cabeza de todas sus ramas del poder público, estos grupos al margen de la ley fortalecen su estructura económica, ya que la inversión que estos tienen en insumos y personal es poca, comparada con las inmensurables ganancias que obtienen para financiar más terrorismo en el país.

En cuanto al tema de corrupción, los grupos armados al margen de la ley hacen negocios con los dueños de las retroexcavadoras para ingresar la maquinaria; en determinadas áreas, el porcentaje para los grupos armados puede llegar hasta un $12 \%{ }^{6}$

Dado que la minería ilegal carece de un control eficiente por parte del Estado, las empresas internacionales que vienen a apropiarse de los recursos con argumentos oportunistas que, ante la situación de escasez de recursos y de ofertas laborales para los habitantes, son aprovechados para explotar cada vez más y dejan de lado el postulado del desarrollo sostenible. Además, generan un desequilibrio en el ámbito ambiental, social y económico que se ve reflejado en la pobreza de la población afectada por esta inequidad y falta de políticas ambientales claras.

En cuanto al factor social, la minería ilegal está acompañada por problemas de pobreza en la población. Esta problemática se debe a que la Nación no ha tenido un crecimiento económico que beneficie a la población con oportunidades de empleo

5 Nataly Jiménez Guantiva, "Análisis del impacto económico de la minería en Colombia y control ejercido por el Estado frente al tema de ilegalidad años 2010-2011" (Tesis de Especialización, Universidad Militar Nueva Granada, 2012), 56-71.

6 Leonardo González Perafán et al., Impacto de la minería de hecho en Colombia. Estudios de caso: Quibdó, Istmina, Timbiquí, López de Micay, Guapi, El Charco y Santa Bárbara (Bogotá: Indepaz, 2013), 49. 
y buenos salarios, lo que contrasta con las posibilidades de ganancias considerables que brindan estos grupos al margen de la ley. ${ }^{\top}$

En el ámbito ambiental, ante la falta de control por parte de los organismos del Estado, la demanda de recursos es más alta que la oferta; esto ocasiona un desequilibrio que llevará al agotamiento de los recursos, ya que estos se consumen en la medida en que sea posible. Además, los impactos son evidentes: el porcentaje de erosión es muy alto, porque se arrasa con la cobertura vegetal, se deteriora la productividad del suelo y se alteran ciclos básicos como el del agua. De igual manera, al destruirse la capa vegetal, hay migración de flora y fauna, puesto que pierden su hábitat natural.

Asimismo, el material particulado que se genera por la actividad de explotación y el ruido de la maquinaria tienen gran impacto en la comunidad, no solo como una problemática ambiental, sino de salud pública por las infecciones respiratorias agudas en población vulnerable como niños y ancianos.

Aunque es de aclarar que los impactos ambientales devienen de cualquier actividad de explotación minera, es evidente que los de la minería ilegal son más fuertes, debido a la ilegalidad y falta de control por parte de las autoridades ambientales.

Lo anterior, sumado a la intención de minimizar costos, implica mayor perjuicio. El Ministerio de Ambiente, Vivienda y Desarrollo Territorial, para citar fuentes oficiales, reporta daños ecológicos por la minería ilegal de oro en diecisiete departamentos. ${ }^{8}$

En cuanto a los impactos en el ámbito social, económico y ambiental, es evidente que el marco normativo existente en el país es precario y la actuación del Estado es mínima, si se equipara con la fuerza que tiene la actividad ilegal y su vínculo con los grupos armados al margen de la ley.

En el objetivo de la Ley 685 de 2001, se establece que la exploración técnica y la explotación de recursos mineros de propiedad estatal y privada debe ser sostenible, es decir, que se garantice su disponibilidad para generaciones futuras sin agotarlos, pero según lo expresado en párrafos anteriores, el crecimiento en la explotación de

González Perafán et al., Impacto de la minería de hecho en Colombia, 73.

8 Procuraduría General de la Nación, "Minería ilegal en Colombia. Informe preventivo" 2011, http://www. procuraduria.gov.co/portal/media/file/MINERIA\%20ILEGAL\%20EN\%20COLOMBIA\%20\%20DOCUMENTO. pdf (acceso abril 13, 2015). 
estos recursos ha sido desmesurado y lo más alarmante es que un gran porcentaje de esta actividad corresponde a la minería ilegal. ${ }^{9}$

Lo anterior lo establece la ley, pero la realidad que se vive en Colombia es muy diferente. La minería ilegal se encuentra en todo el territorio nacional y, al no contar con título minero, evade impuestos y pago por regalías, lo que representa pérdidas económicas para los municipios y el Estado y ocasiona daños ambientales porque no cuenta con estudios previos de impacto ambiental (requisito para obtener el título minero).

La falta de estos estudios impide minimizar los daños ocasionados al ambiente intervenido y conocer los pasivos ambientales que se generan.

\section{Responsabilidades de los entes del poder público en el deterioro al ambiente a causa de la minería ilegal en el resguardo indígena embera katío}

Para el caso de estudio es importante exaltar los roles de cada una de estas ramas e identificar las posibles falencias que se están presentando para contrarrestar el flagelo de minería ilegal en el resguardo indígena del río Alto Andágueda y el sinnúmero de delitos conexos que ponen en riesgo el patrimonio ambiental, étnico y cultural de estas comunidades indígenas.

El presidente de la República, como jefe de la Rama Ejecutiva y autoridad superior ante todas las instituciones legítimamente constituidas y bajo su responsabilidad, tiene la obligación de velar por el cumplimiento de los derechos constitucionales de cada uno de los habitantes del territorio colombiano.

Es preciso instituir programas presidenciales conocidos en el territorio nacional con los que podría hacer presencia la institucionalidad del Estado y así suplir las necesidades de esta comunidad indígena.

Ahora bien, la falta de atención del Alto Gobierno hacia estas comunidades ha permitido que sean permeadas por problemas muy graves para la sociedad colombiana,

Congreso de la República, Ley 685 de 2001, "Por el cual se expide el Código de Minas y se dictan otras disposiciones" (Bogotá: Diario Oficial No. 45.273, 15 de agosto 2001), art. 1. 
que se demuestran en la presencia de grupos armados al margen de la ley y sumen a las comunidades en una degeneración de sus costumbres y hábitos como el cultivo de hoja de coca, la minería ilegal, la prostitución, la explotación laboral, etc.

Parece que estuviéramos retrocediendo en el tiempo cuando damos una mirada a las comunidades asentadas en el Alto Andágueda del Chocó, pues en lugar de avanzar a un desarrollo conjunto de una Nación, más bien se asemeja una reconquista que viene sembrando degradación y acabando con los patrimonios culturales de la Nación.

Al ver las situaciones existentes, podemos decir que el abandono viene desde el Gobierno Central, con falta de atención a los problemas referentes a estos territorios. Las instituciones y sus directivos tienen sobre sus hombros la responsabilidad de brindar atención oportuna y afrontar las consecuencias de las omisiones relacionadas con los problemas que ahí se presentan y que, en este caso, se centran en la minería ilegal.

Por parte del Ministerio de Medio Ambiente y Desarrollo Sostenible se aprecia la carencia de políticas serias y comprometidas con el cuidado y la toma de decisiones contundentes en contra de los infractores de la Constitución, las leyes y los reglamentos que regulan el tema ambiental. Esto ha llevado a que las personas atenten en contra del ambiente, trayendo consigo problemas de salud pública, afectación al componente biofísico y daño paisajístico, entre otros perjuicios que son irreversibles y, de no serlo, requieren mucho tiempo para su recuperación.

Las herramientas y las autoridades deben prevenir, corregir y sancionar, pero las omisiones de las facultades y funciones son las que llevan a que las personas causen estos desastres naturales sin ningún control.

En el ámbito nacional y regional existen entidades como la Autoridad Nacional de Licencias Ambientales (ANLA), la Corporación Autónoma Regional (CAR), el Ministerio de Minas y Energía, la Agencia Nacional Minera, el Ministerio de Salud, el Ministerio de Justicia, las Gobernaciones y las Alcaldías.

Se observa que a pesar de toda su estructura orgánica, estas entidades no están cumpliendo a cabalidad con las funciones. Es notorio el incumplimiento de lineamientos, políticas y reglamentos del Estado que son emitidos para la correcta administración, preservación y aprovechamiento de los recursos naturales, lo que 
deja entrever la corrupción de los funcionarios de turno y, a su vez, el deterioro del ambiente y la mala administración del mismo.

De otro lado, las políticas mineras en el país no han sido serias, sostenidas y responsables con el campo y han tratado de invadir de manera insensata las políticas ambientales, dada la clara descoordinación entre las autoridades que tienen que ver con el tema, pues se ha permitido que las personas exploren y exploten sin permiso ni estudio ambiental, lo que otorga, de alguna manera, legitimidad y legalidad a las solicitudes de formalización minera sin los estudios técnicos necesarios.

La falta de herramientas legales perdurables no ha dado seguridad jurídica a las personas que pueden sustentar su supervivencia en las actividades de minería.

Asimismo, el Gobierno nacional no ha logrado una correcta definición de las clases de minerías existentes en el país, razón por la cual muchas personas que no cumplen con requisitos mínimos establecidos están explotando minerales amparados por la figura de minería tradicional, ancestral y de subsistencia.

Una de las problemáticas más graves que afecta el ambiente y en especial a las fuentes hídricas es la contaminación con mercurio y cianuro, derivada de las explotaciones mineras de aluvión, sobre todo del oro, lo que conlleva una afectación al ambiente y atenta contra la salud pública. A pesar de que es un problema a la vista de las autoridades y que se ha ordenado la reglamentación del uso de sustancias peligrosas y químicas, se observa la omisión por parte del Ministerio de Salud, que deja en manos irresponsables la manipulación de estos contaminantes, sin una efectiva herramienta de control.

En cuanto a la parte normativa, se requiere impulsar leyes para que el Estado combata la minería ilegal, sus problemas conexos y otros inconvenientes generados en estos territorios, toda vez que ellos tienen un trato diferencial reconocido por la Constitución Política de Colombia. Hacen falta herramientas eficaces en la persecución penal contra las personas forasteras que ocasionan estos daños, se llevan los recursos y dejan los problemas ambientales y sociales.

Respecto a la Rama Judicial, se requiere que las autoridades encargadas de administrar justicia en Colombia, dependientes del órgano judicial a quien se delega las facultades para que resuelva o controvierta las decisiones del imputado, sancionen a los ciudadanos infractores de los daños ambientales ocasionados por la actividad 
de minería ilegal dentro del territorio nacional -con base en las evidencias o pruebas presentadas en un juicio-, administren justicia, investiguen las conductas punibles y acusen a los presuntos infractores ante los juzgados y tribunales competentes.

Lo que se observa de la Rama Legislativa es que, en muchas ocasiones, no se acatan las funciones y el Congreso deja que la Administración de turno haga lo que a bien tenga, sin contribuir a los fines esenciales del Estado.

En la ineficacia administrativa de las ramas del Poder Público, se ven los errores y la toma de medidas apresuradas que llevan a los Estados a un abismo sin regreso, con daños irreparables en nuestra sociedad, los recursos naturales renovables y no renovables y daños colaterales que pueden agravar la situación de todo un continente.

Colombia busca confrontar problemas como el aquí tratado, al exigir a sus autoridades la muestra de resultados, pero sin desarrollar estudios que descubran las problemáticas reales y cercanas a las necesidades de las personas que, en ocasiones, tienen a una cadena criminal detrás de ellos y son coaccionadas para obtener los minerales de manera ilícita. Este tipo de problemáticas también se observan en otros países, cuando encontramos que los Estados que han sido explotados se quedan con los problemas sociales y el menoscabo del ambiente, sin que las comunidades o la Administración tengan derecho a obtener provecho de esas explotaciones y mucho menos soluciones a los problemas que estas conllevan.

Vemos poca atención a problemas de tal índole, sin que el Parlamento emita o se preocupe por hacer su trabajo en relación con la explotación de recursos naturales, por lo que una normativa estropeada o inaplicable permita el agotamiento de los recursos naturales e impida la protección seria de los derechos de una sociedad.

\section{Alcance de la política pública}

Es importante diseñar, señalar y difundir las acciones gubernamentales que incluyan objetivos de interés público, dirigidas a satisfacer bienes y servicios enfocados a la protección de derechos y principios fundamentales, basadas en diagnósticos y estudios y con participación de la sociedad.

En el caso en específico, se deben proponer soluciones a corto y largo plazo al fenómeno que se viene presentando con la minería ilegal en Colombia, para que sirvan 
como ejemplo ante la región en experiencias y aplicación de políticas novedosas que permitan la inclusión social.

Como primera medida y de manera urgente, se debe plantear la posibilidad de atacar de manera frontal la problemática con acciones interinstitucionales que fortalezcan las funciones de las entidades comprometidas y que tienen a cargo la protección del ambiente y los recursos naturales renovables y no renovables. Esto facilitará intervenir el problema de la minería ilegal de forma eficiente, eficaz y efectiva con acciones integrales y simultáneas, puesto que muchas de estas comunidades obtienen el sustento de estas actividades. La implementación de soluciones estatales mitigará en algo la ilegalidad y arraigará otras soluciones sociales e incluyentes que permitan la protección del bien común y garantizar un mínimo vital.

Las soluciones y las acciones planteadas se deben sostener con apoyo y seguimiento del Estado para que la ilegalidad no reaparezca y haya una reacción frontal ante los problemas de carácter ambiental y administrativo que asegure el cumplimiento de los fines esenciales del Estado. Estas acciones deben abordarse desde la educación, la protección y conservación de los derechos humanos y la Constitución Política de Colombia.

La réplica de estos conocimientos deberá impactar en la toma de conciencia para lograr la protección y conservación de nuestros recursos con estrategias que permitan desarrollar los objetivos. De ese modo, el Estado se convertirá en un aliado del pensamiento social para iniciar la recuperación de los pasivos ambientales, con la participación de las mismas comunidades y la reparación de otros problemas de salud pública heredados de la minería ilegal, por ejemplo, la presencia del mercurio, pues de acuerdo con estudios de entidades estatales y no estatales, la población colombiana supera los niveles estándar de bioacumulación de este metal en el organismo.

Se cree que lo más importante para las generaciones futuras es la actuación inmediata frente a la problemática y las acciones en contra de toda actividad arbitraria, que deben desplegarse de manera inmediata para dejar un planeta habitable. La tarea hay que iniciarla cuanto antes, pues las advertencias no se hacen esperar. La Tierra agoniza y cada día le aportamos más a su no muy lejana destrucción.

Existen esfuerzos monumentales que vienen haciendo instituciones como la Policía Nacional, de los cuales se resalta el interés en la lucha en contra de la minería 
ilegal. Las herramientas jurídicas actuales son débiles y no tienen la capacidad de hacer frente al problema de la minería ilegal que tanto afecta a nuestro país. Puesto que la Policía es una institución fuerte y con presencia en todos los municipios del territorio nacional, puede desplegar programas y políticas exitosas para combatirla.

\section{Conclusiones}

La poca efectividad de los entes del Estado frente al delito de minería ilegal en el resguardo indígena del río Alto Andágueda en el departamento del Chocó es evidente, lo que desborda el accionar institucional ante la poca e inefectiva existencia de herramientas normativas y administrativas para su prevención y control.

Para superar la problemática que presenta el resguardo indígena embera katío se deben orientar esfuerzos de las entidades competentes adscritas a la rama Ejecutiva, Legislativa y Judicial que permitan contrarrestar el desastre ambiental que está generando este flagelo.

Mientras el Estado no instituya políticas públicas claras alusivas al delito, este se fortalecerá, mutará de manera incontrolable y, con la apropiación del negocio por parte de los grupos armados ilegales, traerá consecuencias irreversibles al componente ambiental natural de este territorio étnico.

La depredación ambiental que ocasiona la actividad ilícita en el resguardo indígena conlleva consecuencias desastrosas en los ecosistemas que comprenden este lugar, así como la limitación de recursos naturales demandados por la población nativa del lugar.

Es preciso estudiar la problemática observada en este resguardo de una manera global y abarcar el ámbito social y ambiental. Si esta población contara con condiciones óptimas de vida, como una vivienda, salud, trabajo y otros derechos constitucionales, no sería vulnerable ante la seducción de las ofertas de grupos al margen de la ley que les ofrecen ciertos beneficios que no les da el Estado.

La problemática ambiental también es un problema de salud pública, debido a la contaminación por mercurio en fuentes hídricas; por ello, es indispensable crear una normativa estructurada y rígida que permita su cumplimiento. 


\section{Recomendaciones}

El conocimiento de la problemática de minería ilegal en el resguardo indígena embera katío del Alto Andágueda confiere una especial atención, si se tiene en cuenta la vulnerabilidad de la población que está siendo atacada por este flagelo nacional que, además de originar múltiples problemas sociales, desprende la triste realidad de destrucción de la riqueza natural de uno de los ecosistemas más representativos del país.

Por lo anterior, es necesario transmitir este estudio de caso, para contribuir a la sensibilización y concientización frente a las consecuencias de la minería ilegal en el patrimonio natural nacional.

\section{Referencias}

Congreso de la República. Ley 685 de 2001, "Por el cual se expide el Código de Minas y se dictan otras disposiciones". Bogotá: Diario Oficial No. 45.273, 15 de agosto 2001.

Garay Salamanca, Luis Jorge (dir.). Minería en Colombia. Institucionalidad y territorio, paradojas y conflicto. Bogotá: Contraloría General de la Nación, 2013.

González Perafán, Leonardo, Carlos Espitia, Pedro Juan Munar, Antonio de la Hoz Ruiz y Luis Fernando Sánchez. Impacto de la minería de hecho en Colombia. Estudios de caso: Quibdó, Istmina, Timbiquí, López de Micay, Guapi, El Charco y Santa Bárbara. Bogotá: Indepaz, 2013.

Jiménez Guantiva, Nataly. "Análisis del impacto económico de la minería en Colombia y control ejercido por el Estado frente al tema de ilegalidad años 2010-2011". Tesis de Especialización, Universidad Militar Nueva Granada, 2012.

Procuraduría General de la Nación. "Minería ilegal en Colombia. Informe preventivo 2011" http://www.procuraduria.gov.co/portal/media/file/MINERIA\%20ILEGAL\%20EN\%20 COLOMBIA\%20\%20DOCUMENTO.pdf (acceso abril 13, 2015).

Tribunal Superior del Distrito Judicial de Antioquia, Sala Civil especializada en restitución de tierras. Sentencia 007 de 23 de septiembre de 2014. M. P. Vicente Landínez Lara. 